\title{
UTERINE TORSION IN STRAIGHT EGYPTIAN ARABIAN MARES, DIAGNOSIS AND COMPARISON BETWEEN ROLLING AND FLANK LAPAROTOMY AS A TREATMENT
}

\author{
M.K. DERBALA and MOSALLAM T.E \\ Animal Reproduction Research Institute-Agriculture Research Center (ARC)-Egypt
}

Received: 28 May 2019; Accepted: 14 July 2019

\begin{abstract}
Uterine torsion is one the most critical conditions affecting pregnant mares in last trimester of pregnancy. The current study was advocated for precise diagnosis of uterine torsion in mares and accordingly application of suitable method of treatment. The study comprised 12 Straight Egyptian Arabian mares suffered from uterine torsion (5-11 months of gestation). Diagnosis was based on symptoms which were intermittent signs of colic, straining and frequent lifting of upper lip. Clinical examination has been applied through rectal examination for detection of direction of broad ligament (clockwise and counterclockwise directions). Blood biochemistry was carried out and only CRP (C-reactive protein) was elevated in $25 \%$ of cases. Ultrasonography was used for detection of fetal viability through rectal and transabdominal scanning. The results of rolling method was $33.3 \%$ live newborn and $66.6 \%$ live dams whereas $66.6 \%$ live newborn and $83.2 \%$ live dams for flank laparotomy. Consequently, flank laparotomy was preferred than rolling method. There were some complications of treatment such as abortion or death of the dam due to uterine rupture. In conclusion, uterine torsion in mares is a serious problem should be diagnosed as early as possible for obtaining good results of treatment as well as standing flank laparotomy is more preferred than rolling method for getting a good results.
\end{abstract}

Key words: uterine, torsion, mare, rolling, flank laparotomy.

\section{INTRODUCTION}

Uterine torsion is an infrequent but serious complication of pregnancy in mares. It may account for $5-10 \%$ of serious dystocia in the equine (Vandeplassche et al., 1972). The degree of torsion can vary from $180^{\circ}$ to $540^{\circ}$, in either a clockwise or counterclockwise direction as viewed from the rear. The broad ligament, or mesometrium, which suspends the uterus, has an extensive base in the sublumbar region, which limits the potential for uterine torsion in the mare compared with the cow. No breed or age predilection has been demonstrated in the horse (Vasey and Russel, 2011).

The causes of uterine torsion in the mare are not well defined, but they include factors such as vigorous fetal movement, rolling of the mare, sudden falls, a large fetus in a relatively small volume of fetal fluid, lack of tone in the pregnant uterus, a long mesometrium, and the presence of a large, deep abdomen (Roberts, 1971 and Taylor et al., 1989).

Corresponding author: Dr. MOSALLAM T.E

E-mail address: mohamed_equine@yahoo.com, tarekelsayedmosallam@yahoo.com

Present address: Animal Reproduction Research InstituteAgriculture Research Center (ARC)-Egypt
The incidence of uterine torsion is more obvious in last trimester of pregnancy and should be suspected in mares presented at 8 months of pregnancy or later with signs of colic (Vasey 1993). These signs include depression, pawing, looking at the flank, restlessness, sweating, inappetance, and frequent urination, sawhorse stance, kicking at the abdomen and rolling (Roberts, 1971 and Pascoe et al., 1981).

Diagnosis of uterine torsion is carried out by rectal palpation. The majority of cases involve torsion of $180^{\circ}$. Through rectal examination, a taught broad ligament is palpable obliquely when crossing the uterus in the direction of the torsion. In cases of clockwise torsion (described from a position standing behind the horse), the left broad ligament will usually be palpable above and horizontal to the uterus coursing cranial and to the right. The right broad ligament may be palpable in a vertical direction passing below the uterus, but this finding is less reliable. In a counterclockwise orientation, the right broad ligament will usually be palpable above and horizontal to the uterus coursing cranial and to the left. The left broad ligament may be palpable in a vertical direction passing below the uterus. Definitive diagnosis of the presence and direction of uterine torsion is critical for non-surgical management. If the operator is not comfortable with the diagnosis of uterine torsion, non-surgical 
correction should not be attempted Riggs (2006). The haematobiochemical parameters such as TLC, TEC, DLC, PCV, ESR, SGPT, total protein, BUN and blood glucose were within normal range (Dabas et al., 2014).

Different techniques such as manual rotation through cervix, rolling, standing flank laparotomy and ventral midline celiotomy have been suggested to correct equine uterine torsion and method of preference should be based on degree of torsion, severity of pain, fetal viability and client's financial constraints (Dabas et al., 2014).

Non-surgical management of equine uterine torsion carries high risks for maternal death and fetal loss (Vandeplassche et al., 1972 and Vasey, 1993). Manual repositioning of the foal through the cervix and rolling the mare significantly endanger the life of the foal and/or the mare (Vasey, 1993). At term, all non-surgical methods predispose to a separation of the allantochorion from the endometrium, with subsequent abortion, premature birth or death of the fetus in almost all cases (Pascoe, 1981 and Vasey, 1993). Ruptures of the uterus or tears of the mesometrium have been reported (Wichtel et al., 1988 and Embertson, 2006).

Surgical techniques have used laparotomy and either manual untwisting of the uterus or hysterotomy followed by correction of the torsion (Vandeplassche et al., 1972 and Pascoe., 1981). Ultrasonic examination was performed to determine the viability of the fetus prior to surgery (Jung et al., 2008). The standing flank approach has been more popular than the ventral midline approach, (Vandeplassche et al., 1972; Ley and Santschi, 1999), (Trotter and Embertson, 1999) and (Embertson, 2006) and the opinion of some authors is that correction is easier using the standing flank approach (Pascoe, 1981) and (Trotter and Embertson, 1999). However, this method also carries risks: the weight of the uterus in the last weeks of pregnancy can cause strangulation and venous congestion of the uterine vessels, which can lead to oedema of the uterine wall. Moreover, the mesometrium is under considerable tension, and if the mare is standing up during laparotomy, this can lead to perforation of the uterus and injuries to the mesometrium during manual retorsion (Vasey, 1993). In cases of heavy congestion of the uterus, correction of torsion has only been possible after hysterotomy and removal of the foetus (Taylor et al., 1989).

Complications arising from uterine torsion include abortion, loss of the cervical mucus plug, premature placental separation, incarceration of the small colon, subcutaneous seroma formation, partial or complete dehiscence of the incision wound, uterine rupture, peritonitis after necrosis, leakage or rupture of the uterine wall, death of the mare from circulatory and endotoxemic shock, irreversible thrombosis, hematomata, extreme venous congestion and reoccurrence of uterine torsion during the same pregnancy (Martens et al., 2008).

Prognosis for survival of mares and foals after uterine torsion varies greatly from $60-70 \%$ and 30 $70 \%$ respectively (Vandeplassche et al., 1972; Pascoe et al., 1981 and Wichtel et al., 1988). However, the present report describe successful correction of uterine torsion in advanced pregnant mares by rolling with modified S chaffer's method under general anesthesia that resulted into birth of healthy foals after completion of normal gestation period (Dabas et al., 2014).

\section{MATERIALS AND METHODS}

1. Ultrasound machine: Ultrasonography was performed using 2 different realtimes B-mode scanners (Esaote Mylab 30- Netherlands) equipped with 5-7.5 MHz frequency LV513 linear-array rectal transducer, and (Shenzhen Well. D -China) equipped with 3.5-5 $\mathrm{MHz}$ convex probe. The scanners have a built-in electronic caliper system for measuring distance, area and circumference, angle and auto follow measurements. Ultrasonic gel (Carboxymethylcellulose) was used as a lubricant during rectal scanning and as a coupling medium during transabdominal scanning.

2. Wooden plank and ropes.

3. Complete surgical set and sterile drapes.

4. Xylazine, Butorphanol and ketamine for general intravenous anesthesia and lidocaine for local infiltration anesthesia.

5. Methods of treatment of the torsion.

5.1. Rolling method:

Rolling was applied after (induction of general intravenous anesthesia) by placing the mare on lateral recumbency on the site of the direction of the torsion then tying the forelimbs and hind limbs separately then rolling in the same direction of the torsion with applying a plank of wood to stabilize the fetus while the mare is rotated (Guthrie, 1982) (Fig.1) . 
Fig. (1):

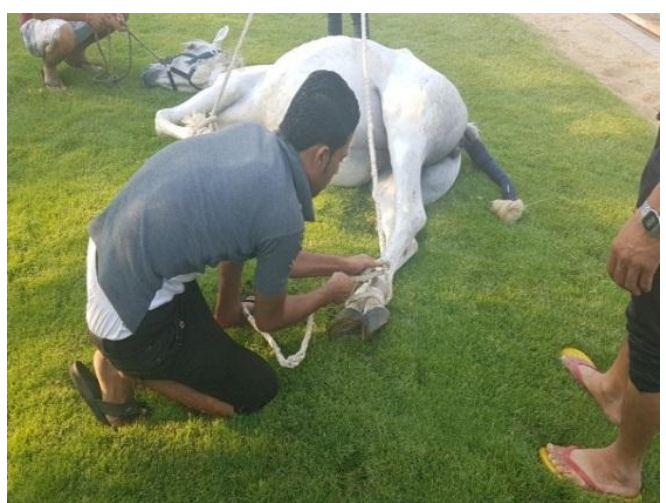

(a) General intravenous anesthesia then tying the forelimbs and hind limbs

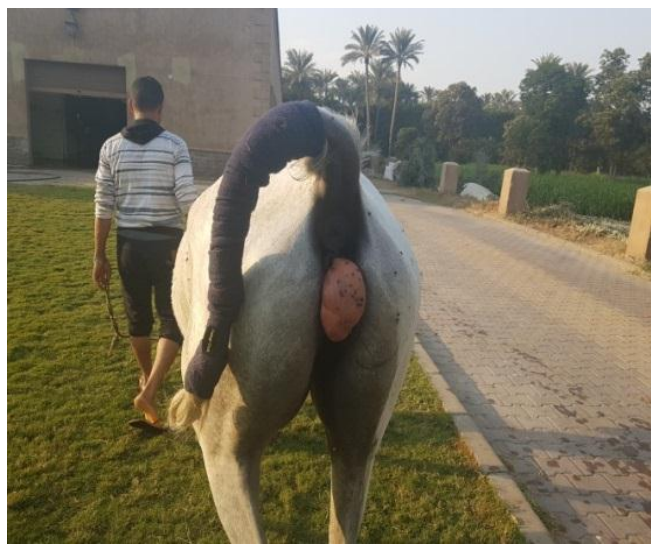

(c) Appearance of fetal sac after correction of the uterine torsion in expulsive stage.

5.2. Standing flank laparotomy:

The mare was placed in stocks. Sedation with Xylazine was done followed by continuous rate infusion using a combination (Xylazine with butorphanol). The flank region was aseptically prepared then desensitized for operation using lidocaine. Skin and subcutaneous tissue were incised

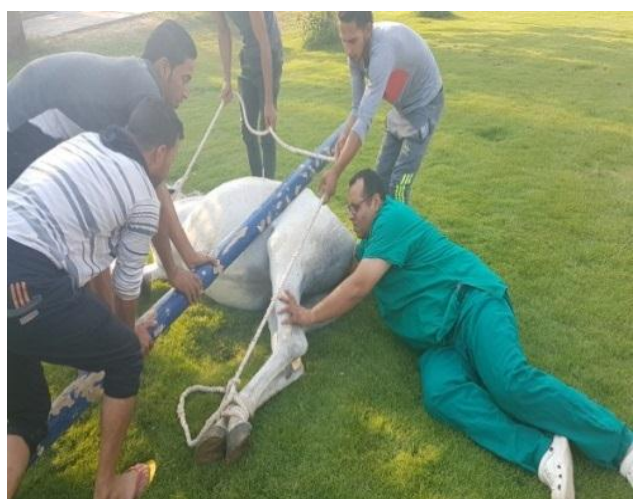

(b) Applying a plank of wood on the abdomen then rolling of the mare in the same direction of the torsion

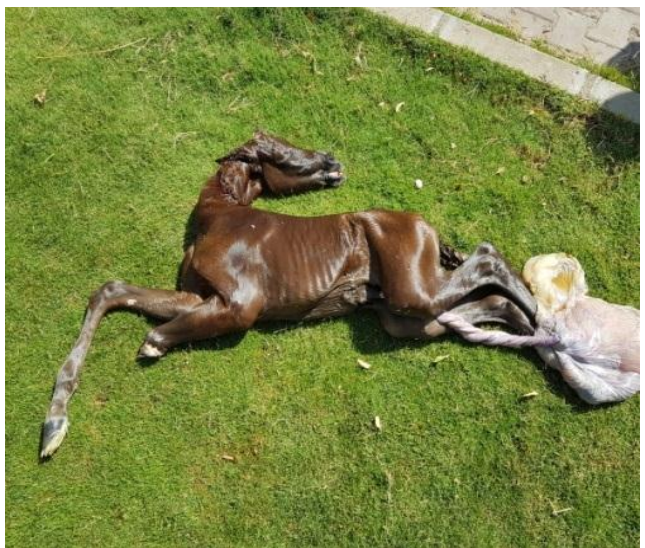

(d) Full term dead fetus after correction of uterine torsion

in a vertical manner, then the external, internal and transvers abdominal muscle were divided in the direction of their fibers then perforation of the peritoneum. Hand was introduced to hold a part from the fetus then repelling and returning the uterus to normal position (Fig. 2).

Fig. (2):
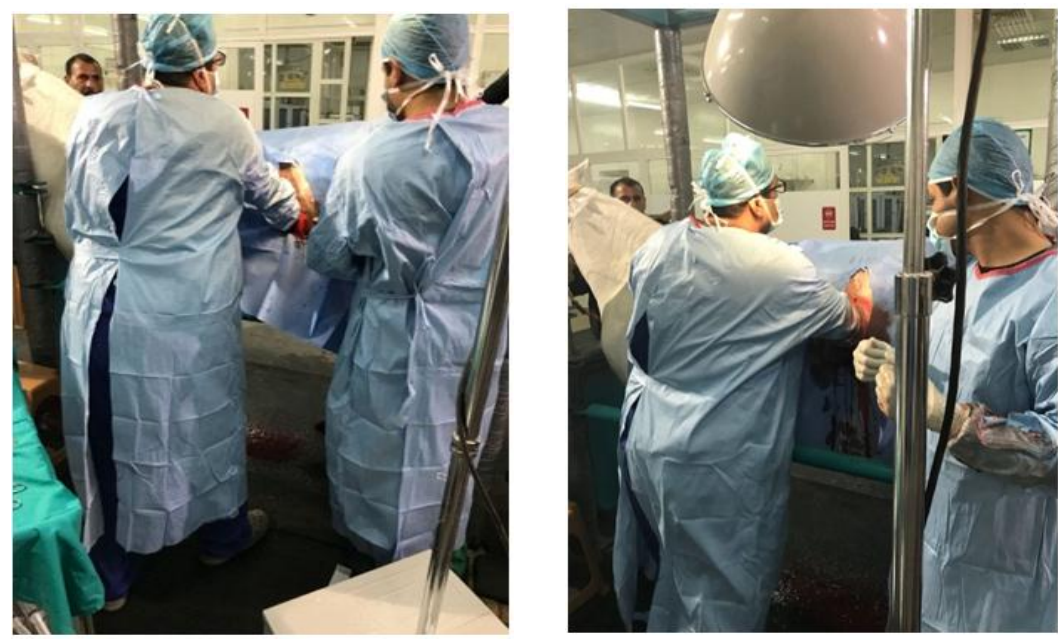

a: Introduction of the hand and grasping of a part from the fetus then rotation for correction of the uterine torsion 

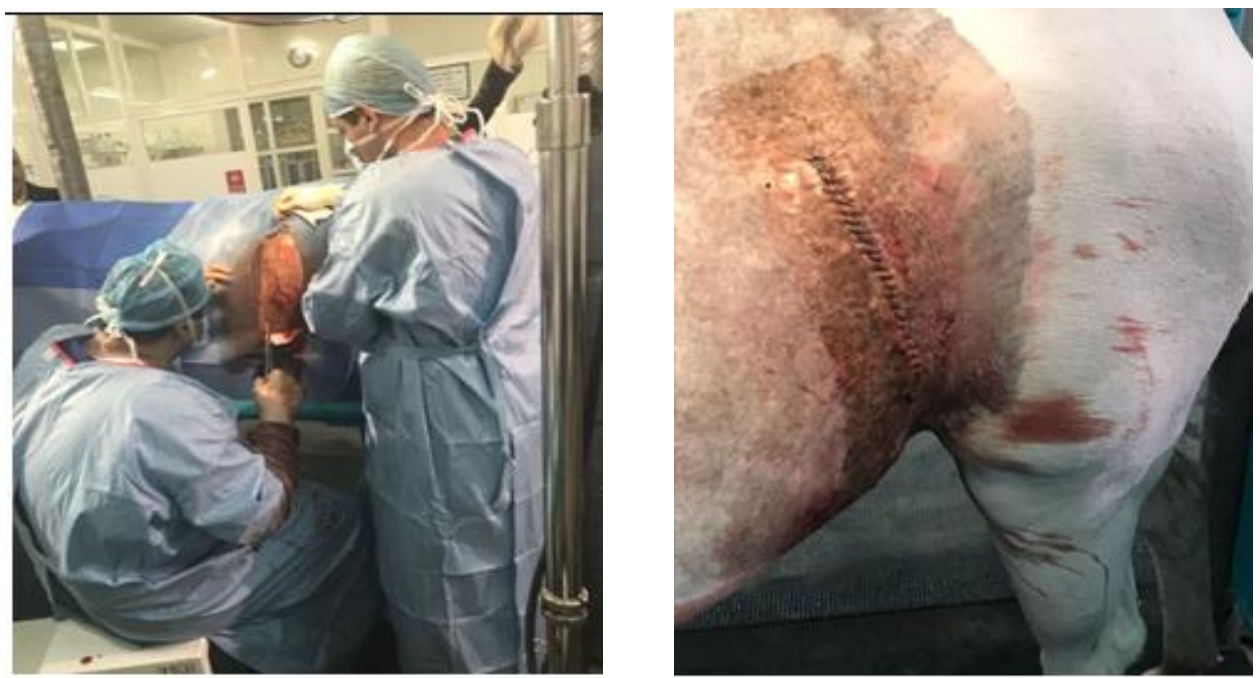

b: Closure of the wound after correction of the uterine torsion with using simple continuous pattern in the skin

\section{RESULTS}

\section{Symptoms:}

This study comprised 12 Arabian mares that subjected to diagnosis of uterine torsion and subsequently to treatment with either rolling or flank laparotomy. Diagnosis was carried out through symptoms and clinical examination. These symptoms were depression, periodic pawing, looking at the flank, sweating, straining without urination, sawhorse stance and occasionally mares showed frequent lifting of upper lips with extension of head and neck and rectal examination provoked straining.

\section{Clinical examination:}

Through rectal examination, the uterine torsion was diagnosed through palpation of broad ligament and determination of its orientation. Uterine torsion was

Fig. (3):

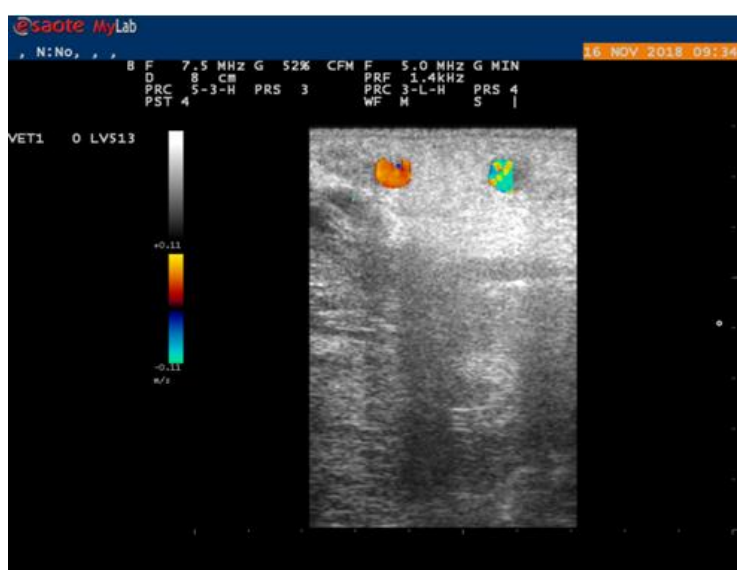

(a) Transrectal ultrasonography showing inaccessibility of reaching the fetus and imaging of blood vessels crossing over the uterus either clockwise torsion or counterclockwise (described from aposition standing behind the mare). In clockwise torsion, the left broad ligament was palpated crossing to the right over the uterus with feeling of large blood vessels pulsating. While in counterclockwise, the right broad ligament was palpated crossing to the left side over the uterus. In both clockwise and counterclockwise the fetus was difficult to be palpated as it was like pushed forward into the abdomen and after correction it came back into palpable position.

Transrectal ultrasonography was applied to detect the position of the fetus, any signs indicating viability and blood vessels in the broad ligament crossing over the uterus. Transabdominal ultrasonography was applied for evaluation of the fetal viability and involvement of placenta (Fig. 3).

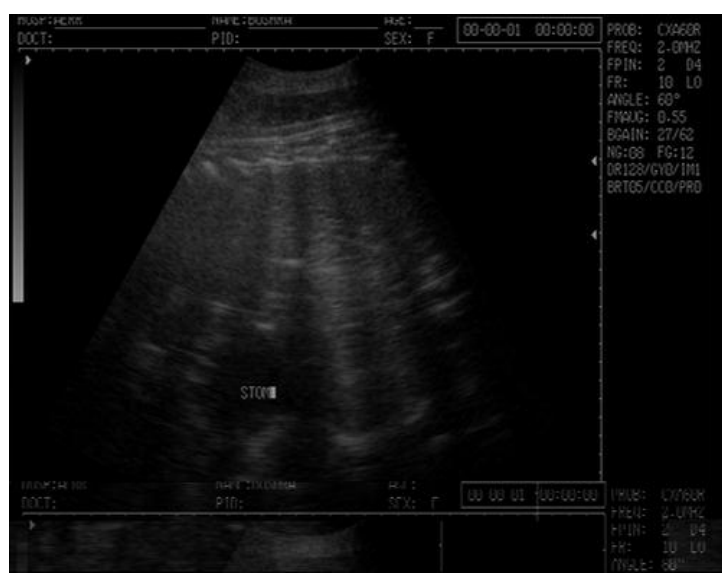

(b) Transabdominal ultrasonography for evaluation of fetal viability 


\section{Blood biochemistry:}

Serum samples were collected from 12 mares under study for measurement of $\mathrm{C}$-reactive protein, albumin and total protein. The results were within normal for albumin and total protein while CRP was elevated $25 \%$ (4/12) of cases.

\begin{tabular}{cccc}
\hline Cases & $\begin{array}{c}\text { CRP } \\
\mathbf{m g} / \mathbf{L}\end{array}$ & $\begin{array}{c}\text { Albumin } \\
\mathbf{m g} / \mathbf{d}\end{array}$ & $\begin{array}{c}\text { TP } \\
\text { g/L }\end{array}$ \\
\hline 1 & - & 3.3 & 7.3 \\
\hline 2 & - & 2.9 & 7 \\
\hline 3 & 6 & 2.4 & 6.5 \\
\hline 4 & - & 3 & 6.7 \\
\hline 5 & - & 3.1 & 6.9 \\
\hline 6 & - & 2.9 & 7.2 \\
\hline 7 & - & 2.6 & 7.7 \\
\hline 8 & 6 & 3 & 5.9 \\
\hline 9 & 12 & 3 & 6.8 \\
\hline 10 & 12 & 3.5 & 6.7 \\
\hline 11 & - & 2.7 & 6.5 \\
\hline 12 & - & 3 & 6 \\
\hline
\end{tabular}

\section{Treatment:}

The method of treatment in this study was determined according to the owner preference (financial issue). Two methods of treatment were carried out in this study, rolling and standing flank laparotomy. The evaluation of the results of both methods is illustrated in the tables (1,2 and 3).

Table (1):

\begin{tabular}{|c|c|c|c|c|}
\hline \multirow{2}{*}{$\begin{array}{l}\text { Months of } \\
\text { gestation }\end{array}$} & \multirow{2}{*}{$\begin{array}{c}\text { Number of } \\
\text { mares }\end{array}$} & \multicolumn{2}{|c|}{ Method of treatment } & \multirow[b]{2}{*}{ Result of treatment for dam and fetus } \\
\hline & & Rolling & Flank lapa. & \\
\hline 5 & $1(8.3 \%)$ & - & 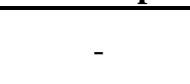 & Death due to delay in treatment \\
\hline 6 & $1(8.3 \%)$ & + & - & Death after treatment due to uterine rupture \\
\hline 7 & $1(8.3 \%)$ & + & + & Death of the dam after operation \\
\hline 7 & $1(8.3 \%)$ & - & + & Abortion 2 days later + dam survive \\
\hline 7 & $1(8.3 \%)$ & - & + & Complete gestation + birth of healthy newborn \\
\hline 8 & $3(25 \%)$ & - & + & Complete gestation + birth of healthy newborn \\
\hline 8 & $2(16.6 \%)$ & + & - & Complete gestation + birth of healthy newborn \\
\hline 11 & $2(16.6 \%)$ & + & - & Birth of dead newborn after correction \\
\hline
\end{tabular}

In this study there was a case died $(8.3 \%)$ due to delay in treatment which lead to uterine rupture (Fig. 4). The signs were moderate responded to analgesics, consequently the owner delayed in sending the mare to the clinic. There was a case lost after trying a rolling method without a correction of torsion then sent to laparotomy yet it died.

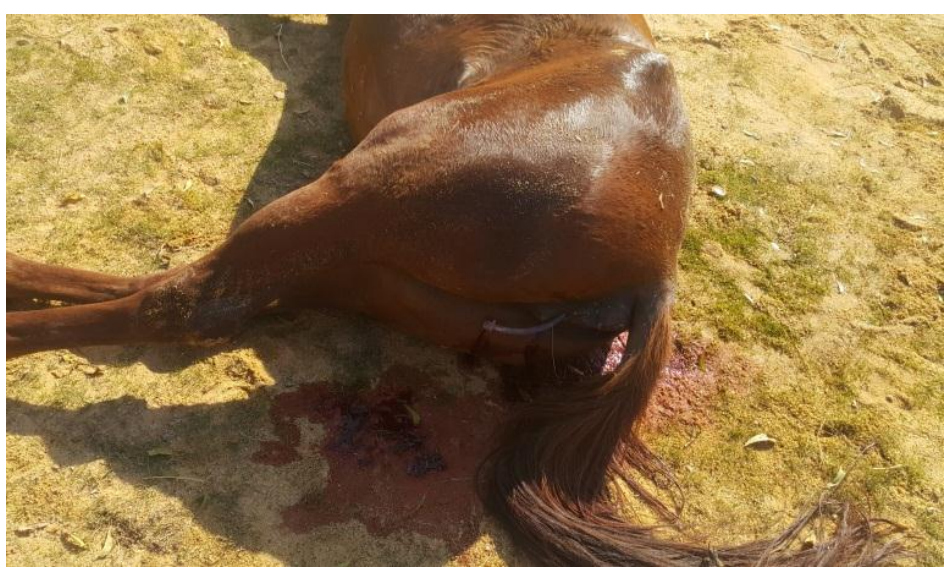

Fig. 4: Showing a dead mare due to uterine rupture as a result of delay in treatment and correction 
Table 2: Showing the results of rolling method on obtaining live newborn and live dam.

\begin{tabular}{|c|c|c|c|}
\hline $\mathbf{N}(6)$ & Live newborn & Live dam & Causes \\
\hline 1 & $-\quad(16.6 \%)$ & $-\quad(16.6 \%)$ & Death-uterine rupture \\
\hline 1 & $-\quad(16.6 \%)$ & $-\quad(16.6 \%)$ & No correction \\
\hline 2 & $2(33.3 \%)$ & $2(33.3 \%)$ & - \\
\hline \multirow[t]{2}{*}{2} & $-\quad(33.3 \%)$ & $2(33.3 \%)$ & Dead fetus in expulsive stage \\
\hline & $33.3 \%$ & $66.6 \%$ & \\
\hline
\end{tabular}

The rolling methods resulted in $33.3 \%$ live newborn after normally passing the gestational period as well as live dams $(66.6 \%)$. Whereas the results obtained from standing flank laparotomy was $66.6 \%$ live newborn and $83.2 \%$ live dams (tables 2,3 ).

Table 3: Showing the results of standing flank laparotomy method on obtaining live newborn and live dam.

\begin{tabular}{cccc}
\hline $\mathbf{N}(6)$ & Live newborn & Live dam & Causes \\
\hline 1 & $-(16.6 \%)$ & $-(16.6 \%)$ & Death after operation \\
\hline 1 & $-(16.6 \%)$ & $+(16.6 \%)$ & Abortion 2 days later \\
\hline 4 & $4(66.6 \%)$ & $+(66.6 \%)$ & - \\
\hline
\end{tabular}

\section{DISCUSSION}

Uterine torsion is one of the most serious causes of dystocia in equine (Vandeplassche et al., 1972), and no breed or age predilection has been demonstrated in the horse (Vasey and Russel, 2011) while as it was noted in current study that Abayyan Arabian Strain is more common to be affected (8/12) with uterine torsion. This strain is characterized high activity and light movement allover other Arabian strains and it may be a heritable cause leading to uterine torsion due to high activity of the dam and the fetus.

The causes of uterine torsion still are not accurately known, but there are many predisposing factors, such as vigorous fetal movement, rolling of the mares, sudden falls, a large fetus in a relatively small volume of fetal fluid and lack of tone in the pregnant uterus (Roberts, 1971) and (Taylor et al., 1989), comparatively with the current study, there was a similarity in predisposing factors which was high movement and irritability that is the characteristic features of Abayyan Arabian Strain affecting the fetus as well.

In this study, the cases of torsion that were recorded began from 5 months of pregnancy till full term, while in other studies like that have been carried out by (Vasey, 1993), showed high incidence of uterine torsion began at 8 months of pregnancy, and it might be due to breed, age or geographical differences.
Diagnosis of uterine torsion in mares includes many aspects such as symptoms that recorded (Roberts, 1971) and (Pascoe et al., 1981) that was depression, pawing, looking at the flank, restlessness, sweating, frequent urination, kicking at the abdomen. In our current study, many similar signs were recorded in addition to frequent lifting of the upper lip in a manner similar to Flehmen's posture in stallions as well as taking the position of urination without micturition. Blood chemistry was carried out and the results were within normal ranges (Dabas et al., 2014), while in the current study the CRP was elevated in $25 \%$ of affected cases.

Clinical examination for diagnosis included rectal examination and palpation of broad ligament and determination of its direction. In clockwise torsion, the left broad ligament was palpated crossing to the right side over the uterus while in counterclockwise, the right broad ligament was palpated crossing to the left side over the uterus, and these results were mentioned similarly by Riggs (2006), moreover in the present study blood vessels were felt crossing within broad ligament and was depicted using color Doppler ultrasound, furthermore the fetus was pushed forward making its accessibility was difficult.

The viability of the fetus was checked using transrectal and transabdominal ultrasound for determination of the method of treatment, and the similar method was carried out by Jung et al. (2008). 
The management of uterine torsion in the current study included rolling method and standing flank laparotomy method. The method of treatment was determined according to the preference of the owner depending on the costs of each method. When comparing the 2 methods in the current study, through obtaining live foal and live dam, the rolling method resulted in $33.3 \%$ live foal after normal completion of gestation period and $66.6 \%$ live dams. Whereas, the standing flank laparotomy resulted in $66.6 \%$ live foals and $83.2 \%$ live dams, these results concur with that mentioned by Dabas et al. (1981). But on the other hand, the results of standing flank laparotomy method in the current study are more better in survival of both foal and dams, consequently the flank laparotomy is the preferred method as reported by some authors (Vandeplassche et al., 1972; Pascoe et al., 1981; Ley and Santschi, 1999; Trotter and Embertson, 1999, and Embertson, 2006). Some complications have been reported after correction of uterine torsion in mares such as abortion, uterine rupture, shock and death of the dam (Taylor et al., 1989) and Martens et al., 2008), and similarly in the current study there was abortion 2 days later after correction of the torsion (8.3\%) as well as death after rolling due to uterine rupture $(8.3 \%)$.

\section{CONCLUSION}

From the current study, we can conclude that early diagnosis of uterine torsion is very critical as well as the determination of the suitable method of treatment. Furthermore, the standing flank laparotomy is better in results than rolling for obtaining a live foal and live dams.

\section{REFERENCES}

Dabas, V.S.; Chaudhari, N.F.; Chaudhari, C.F. and Bhatt, R.H. (2014): Uterine torsion and its management in advanced pregnant mares. IntasPolivet, Vol 15(II): 263-265.

Embertson, RM. (2006): The uterus and ovaries. In: Auer JA, Stick JA, editors. Equinesurgery. 3rd edn. Saunders, Philadelphia, 855-864.

Guthrie, R.G. (1982): Rolling for correction of uterine torsion in a mare. Journal of the American Veterinary Medical Association 181(1), 66-67.
Jung, C.; Hospes, R.; Bosted, H. and Litzke (2008): Surgical treatment of uterine torsion using a ventral midline laparotomy in 19 mares. Australian Veterinary Journal. Vol. 86, No 7, July.

Ley, WB. and Santschi, RK. (1999): Examination and surgery of the uterus. In: Wolfe DF, Moll HD, editors. Large animal urogenital surgery. Wiliams and Wilkins, Baltimore.

Martens, K.A.; Govaere, J.L.J.; Hoogewijs, M.K.; Lefevre, L.; Nollet, H.; Vlaminck, L.; Chiers, $K$. and Kruif, A. (2008): Uterine torsion in the mare: a review and three case reports Vlaams Diergeneeskundig Tijdschrift,

Pascoe, JR.; Meagher, DM. and Wheat, JD. (1981): Surgical management of uterine torsionin the mare: A review of 26 cases. J. Am. Vet. Med. Assoc; 179: 351-354.

Riggs, M. (2006): How to perform non-surgical correction of acute uterine torsion in the mare. AAEP proceedings, 256-258.

Roberts, S.J. (1971): Diseases and accidents of gestation. In: Roberts S.J. (Editor). Veterinary Obstetrics and Genital Diseases. $2^{\text {nd }}$ ed. Edwards Brothers, Inc., Michigan, p.179-200.

Taylor, T.S.; Varner, D.D.; Martin, M.T.; Blanchard, T.L.; Scrutchfield, W.L. and Elmore, R.G. (1989): Management of Dystocia in Mares: Uterine Torsion and Caesarean Section. Compendium on Continuing Education for the Practicing Veterinarian 11, 1265-1273.

Trotter, GW. and Embertson, RM. (1999): The uterus and ovaries. In: Auer JA, Stick JA, editors. Equine surgery. 2nd edn. Saunders, Philadelphia: 750-761.

Vandeplassche, M.; Spincemaille, J.; Bouters, R. and Bonte, P. (1972): Someaspects of equine obstetrics. Equine Vet. J; 4: 105-13.

Vasey, J.R. (1993): Uterine Torsion. In McKinnon A.O., VossJ.L. (Editors). Equine Reproduction. Williams \& Wilkins, Philadelphia, p. 456-460.

Vasey, J. and Russel, T. (2011): Uterine torsion, chapter 252, pp 2435-2440. Equine Reproduction, Second Edition. Edited by Angus O. McKinnon, Edward L. Squires, Wendy E. Vaala and Dickson D. Varner, Blackwell Publishing Ltd.

Wichtel, JJ.; Reinertson, EL. and Clark, TL. (1988): Nonsurgical treatment of uterine torsionin seven mares. J. Am. Vet. Med. Assoc; 193: 337-333. 


\title{
انفتال الرحم في الأفراس العربية الأصيلة ، التشخيص ومقارنة بين الدوران وشق البطن الجانبي كطرق علاجية
}

\author{
محمد كمال درباله ، طارق السبي مسلم
}

Email: Mohamed_equine@yahoo.com, tarekelsayedmosallam@yahoo.com Assiut University web-site: www.aun.edu.eg

إن التواء الرحم من أكثر المشاكل الخطيرة التي تؤثر على الأفراس في المرحلة الأخيرة من الحمل، وقد أجريت هذه الدراسة

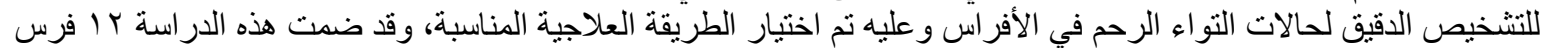

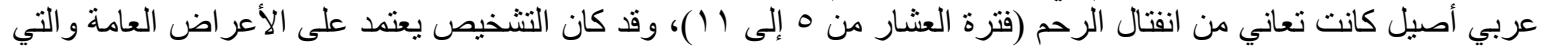

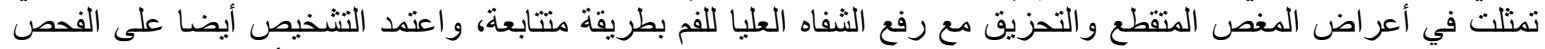

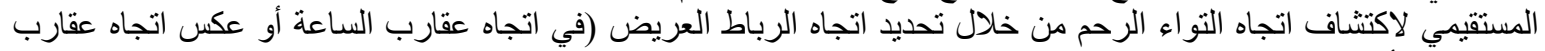

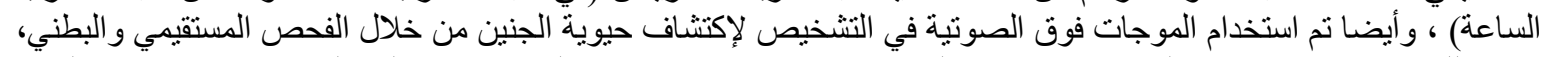

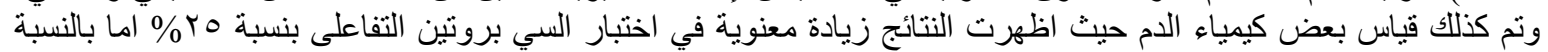

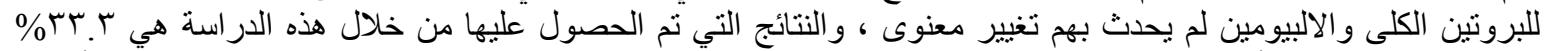

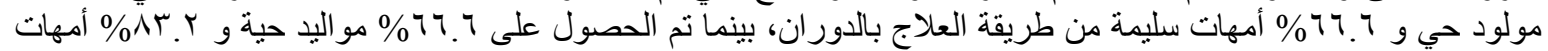

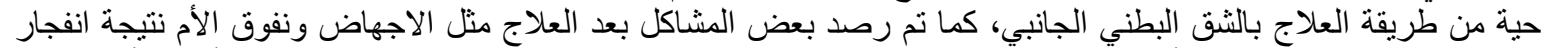

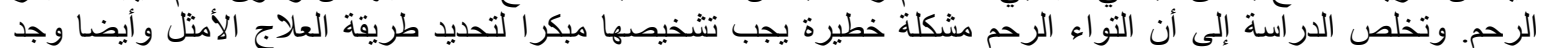
بالدر اسة أن الثق البطني الجانبي يفضل إنى في النتائج عن طريقة الدوران. 